\title{
Genetic polymorphisms among and between blast disease resistant and susceptible finger millet, Eleusine coracana (L.) Gaertn.
}

\author{
Dipnarayan Saha ${ }^{1}+^{*}$, Rajeev Singh Rana ${ }^{1}$, Lalit Arya ${ }^{1}$, Manjusha Verma ${ }^{1}$, \\ M. V. Channabyre Gowda ${ }^{2}$ and Hari D. Upadhyaya ${ }^{3}$ \\ ${ }^{1}$ Division of Genomic Resources, ICAR-National Bureau of Plant Genetic Resources, Pusa Campus, New Delhi \\ 110012, India, ${ }^{2}$ All India Co-ordinated Small Millets Improvement Project, ICAR, GKVK, Bengaluru-560065, \\ India and ${ }^{3}$ International Crops Research Institute for the Semi-Arid Tropics, Patancheru, Hyderabad 502324, \\ India
}

\section{Received 4 August 2015; Accepted 8 January 2016}

\begin{abstract}
Fungal blast disease is one of the major constraints in finger millet production. Breeding for disease resistance in finger millet, needs characterization of genetic polymorphism among and between the resistant and susceptible genotypes. In total, 67 finger millet genotypes, which are resistant or susceptible to fungal blast disease, were analysed using sequence-related amplified polymorphism (SRAP) and simple sequence repeat (SSR) markers to assess genetic variations and select diverse parents. Twelve each of SRAP and SSR primers produced 95.1 and $93.1 \%$ polymorphic bands and grouped them into unweighted pair-group method with arithmetic average clusters. Two of the finger millet genotypes, IE 4709 (blast resistant) and INDAF 7 (susceptible) were distinguished as most diverse genotypes as parents. Several genotype-specific bands observed with SSR primers are potential in developing genotype-specific markers. A high genetic diversity within the resistant and susceptible genotypes, rather than between them, was revealed through Nei's gene diversity $(b)$ index and analysis of molecular variance. The finding helps us to understand the extent of genetic polymorphism between blast disease resistant and susceptible finger millet genotypes to exploit in resistance breeding programs.
\end{abstract}

Keywords: finger millet, genetic variability, resistant and susceptible genotypes, sequence related amplified polymorphism (SRAP), simple sequence repeat (SSR)

\section{Introduction}

Finger millet (Eleusine coracana subsp. coracana Gaertn.) is emerging as one of the potential grain crops for food and nutritional security, climate resilient farming and agricultural diversification. The allotetraploid, finger millet $(2 n=$

*Corresponding author. E-mail: dipsaha72@yahoo.com tPresent address: Division of Crop Improvement, ICAR-Central Research Institute for Jute and Allied Fibres, Barrackpore, Kolkata 700120, India.
$4 x=36$; genome AABB) belongs to the family Poaceae and subfamily Chloridoideae. Finger millet cultivation is spread in many parts of the eastern and southern Africa and in South Asia. Millions of poor farmers and consumers depend on finger millet as a subsistence food and feed grain. Finger millet grains are packed with high nutrition, dietary fibre content (15-20\%) (Chethan and Malleshi, 2007), essential amino acids (44.7\%) (Mbithi-Mwikya et al., 2000) and balanced mineral compositions, such as calcium (344 mg/100 g) (Upadhyaya et al., 2011), zinc $(1.3 \mathrm{mg} / 100 \mathrm{~g})$, iron $(4.4 \mathrm{mg} / 100 \mathrm{~g})$ and phosphorus 
(180.4 mg/100 g) (Singh and Raghuvanshi, 2012). Finger millet as a crop can withstand extreme climatic conditions, thus considered as one of the most potential future agricultural crops for the difficult ecosystems.

Blast disease, caused by the fungus Magnaporthe grisea, seriously affects production, consumption and trade of finger millet (Lenne et al., 2007; Babu et al., 2013). The average yield loss due to blast disease is around $28-36 \%$ (Rao, 1990; Prajapati et al., 2013). The traditional management of blast disease includes fungicides, which is expensive to the poor farmers and environmentally unsafe. Alternatively, development of durable-resistant variety is a more practical approach to manage blast disease in finger millet (Nagaraja et al., 2012). Global collections of finger millet germplasm were evaluated to develop core (Gowda et al., 2007) and minicore collections (Upadhyaya et al., 2010; Upadhyaya et al., 2011). Accessions of finger millet were also evaluated under field conditions to identify blast disease resistant and susceptible genotypes against various isolates of $M$. grisea (Nakayama et al., 2005; Takan et al., 2012; Babu et al., 2012; Babu et al., 2013). Since, it is a self-pollinated crop a limited genetic diversity is expected within a gene pool of popular cultivars and landraces. Thus, it is important to assess the genetic variation in selected trait-specific genotypes before exploiting them in a resistance breeding program. Molecular markers, such as, random amplified polymorphic DNA (RAPD), restriction fragment length polymorphism (RFLP), simple sequence repeats (SSRs) and expressed sequence tags-SSRs (EST-SSRs) were employed in finger millet to assess genetic variation and construction of linkage maps (Salimath et al., 1995; Fakrudin et al., 2004; Babu et al., 2007; Dida et al., 2008; Panwar et al., 2010; Arya et al., 2013). Recently, Babu et al. (2014) reported comparative genomic association of blast disease resistant phenotype and EST-SSR markers in finger millet. In the present study, we examined the genetic polymorphism in blast disease resistant and susceptible finger millets through two polymerase chain reaction (PCR)-based markers, Sequence related amplified polymorphism (SRAP) and genomic SSRs. We report identification of diverse resistant and susceptible genotypes, which will help us to set up a resistance breeding program for mapping and mining of superior alleles and understand host-pathogen interaction mechanisms.

\section{Materials and methods}

\section{Plant materials, genomic DNA extractions and PCR amplification}

In total, 67 finger millet genotypes, including 45 blast disease resistant and 22 susceptible, were selected for genetic polymorphism analysis (Table 1 and Supplementary
Table S1). The resistant and susceptible information of the genotypes was either derived from the genebank information submitted by the breeders or published literature of various forms (Rajanna et al., 2000; Mantur et al., 2001; Nagaraja et al., 2007; Babu et al., 2013; Babu et al., 2014). Genomic DNA extracted from the fresh leaves of all finger millet accessions using the Cetyl trimethyl ammonium bromide method (Doyle and Doyle, 1990) were used for PCR amplifications. Out of 154 combinations of SRAP (Li and Quiros, 2001) and 33 SSR primer pairs (Dida et al., 2007) screened, 12 combinations from both marker types, which produced satisfactory and polymorphic bands in two each highly resistant (GPU 28 and IE 1012) and susceptible (PR-202 and GE-1857) finger millet genotypes were chosen to profile the 67 finger millet genotypes (Supplementary Table S2). The PCR was performed in each $25 \mu \mathrm{l}$ of reaction volume consisting of $100 \mathrm{ng}$ of genOmic DNA, 1.0 unit of Taq DNA polymerase (Fermentas Inc, USA), $1.0 \times \mathrm{PCR}$ buffer with $\left(\mathrm{NH}_{4}\right) \mathrm{SO}_{4}, 2.0 \mathrm{mM} \mathrm{MgCl}_{2}$, $0.2 \mathrm{mM}$ dNTP mix and $0.8 \mu \mathrm{M}$ each forward and reverse primers. The PCR program used for SRAP primer amplification included denaturation at $94^{\circ} \mathrm{C}$ for $10 \mathrm{~min}, 5$ cycles of $94^{\circ} \mathrm{C}$ for $45 \mathrm{~s}, 35^{\circ} \mathrm{C}$ for $1 \mathrm{~min}$ and $72^{\circ} \mathrm{C}$ for $2 \mathrm{~min}$, followed by 35 cycles at $94^{\circ} \mathrm{C}$ for $45 \mathrm{~s}, 50^{\circ} \mathrm{C}$ for $1 \mathrm{~min}$ and $72^{\circ} \mathrm{C}$ for $1 \mathrm{~min}$. The final extension of PCR products was carried out at the $72^{\circ} \mathrm{C}$ for $5 \mathrm{~min}$. For the SSR amplification, PCR program included a touchdown program: denaturation at $95^{\circ} \mathrm{C}$ for $5 \mathrm{~min}, 10$ cycles at $95^{\circ} \mathrm{C}$ for $45 \mathrm{~s}$, touchdown primer annealing started at the $65^{\circ} \mathrm{C}$ for 1 min with a gradual decrease in temperature of $1^{\circ} \mathrm{C}$ per cycle for the remaining 9 cycles, and $72^{\circ} \mathrm{C}$ for $1 \mathrm{~min}$. The PCR products were further amplified for 35 cycles at $94^{\circ} \mathrm{C}$ for $45 \mathrm{~s}, 55^{\circ} \mathrm{C}$ for $1 \mathrm{~min}, 72^{\circ} \mathrm{C}$ for $1 \mathrm{~min}$ and a final extension of strands at $72^{\circ} \mathrm{C}$ for $5 \mathrm{~min}$. The SRAP and SSR primer amplification products were resolved on ethidium bromide-stained 1.8\% agarose gel and 3.0\% MetaPhor ${ }^{\mathrm{TM}}$ Agarose (Lonza Inc, USA) gel, respectively, and the gel images were recorded using gel documentation and analysis system, G: BOX (Syngene, USA).

\section{Molecular marker scoring and data analysis}

Both the SRAP and SSR produced bands were considered as dominant markers and only the clear and reproducible bands from two repeated SRAP and SSR amplifications were scored as discrete variables for the presence (1) and absence (0) across the 67 finger millet genotypes. The ' 1 ' and ' 0 ' binary data matrices were separately scored for SRAP and SSR analysis. Further, a locus was considered polymorphic if its frequency was $\leq$ to 0.99 . The mean number of alleles was estimated using the formula $\mathrm{A}=(1 / \mathrm{K})$ $\sum n_{\mathrm{i}}$; where $\mathrm{K}$ is the number of locus and $n_{\mathrm{i}}$ is the number of alleles detected per locus. The polymorphic information 
Table 1. List of 67 finger millet genotypes and blast resistant or susceptibility traits

\begin{tabular}{|c|c|c|c|c|c|c|c|}
\hline $\begin{array}{l}\text { Sl. } \\
\text { No. }\end{array}$ & $\begin{array}{l}\text { Accession num- } \\
\text { bers (IC/IE) }\end{array}$ & $\begin{array}{l}\text { Popular/ } \\
\text { other name }\end{array}$ & $\begin{array}{l}\text { Known response to } \\
\text { blast disease }\end{array}$ & $\begin{array}{l}\text { Sl. } \\
\text { No. }\end{array}$ & $\begin{array}{l}\text { Accession num- } \\
\text { bers (IC/IE) }\end{array}$ & $\begin{array}{l}\text { Popular/other } \\
\text { names }\end{array}$ & $\begin{array}{l}\text { Known response to } \\
\text { blast disease }\end{array}$ \\
\hline 1. & - & BAU 8 & LB-R & 35. & IC 410115 & VR 708 & LB-S \\
\hline 2. & IC 474231 & GE-4987 & LB-R & 36. & IC 403077 & PES-400 & LB-S \\
\hline 3. & IC 312307 & GPU 26 & LB-R & 37. & IC 474181 & INDAF 8 & LB-S \\
\hline 4. & - & TNAU 1204 & LB-R & 38. & IC 410123 & PR-202 & High B-S \\
\hline 5. & - & BAU 9 & LB-R & 39. & IC 474182 & INDAF 9 & B-S \\
\hline 6. & - & BAU 10 & LB-R & 40. & IE 3618 & RAU-8 & B-S \\
\hline 7. & IC 473819 & GE-4851 & LB-R & 41. & IC 475067 & GE-1857 & High B-S \\
\hline 8. & IC 312321 & L-5 & LB-R & 42. & IC 474180 & INDAF 7 & B-S \\
\hline 9. & - & GE-5525 & LB-R & 43. & IC 403096 & HR-911 & B-S \\
\hline 10. & IC 473976 & GE-4920 & LB-R & 44. & IC 409022 & VL-315 & $F \& N$ B-R \\
\hline 11. & IC 565523 & GPU 48 & LB-R & 45. & - & KM-252 & High B-S \\
\hline 12. & - & GPU 67 & LB-R & 46. & IC 402574 & HR-374 & B-R \\
\hline 13. & IC 410116 & GPU 28 & High LB-R & 47. & - & $\mathrm{K}-7$ & LB-S \\
\hline 14. & IE 1012 & GE-669 & High LB-R & 48. & IC 410120 & OEB-10 & $B-R$ \\
\hline 15. & - & $18 \mathrm{IE}$ & LB-R & 49. & IC 75473 & Hullubele & B-S \\
\hline 16. & - & GPU 45 & LB-R & 50. & IE 6634 & INFM 95001 & B-S \\
\hline 17. & IC 312290 & VL 149 & LB-R & 51. & IE 5870 & Acc. No. 2720 & B-S \\
\hline 18. & IC 259126 & PR 230 & LB-R & 52. & IE 6082 & $\begin{array}{l}\text { Accn. No. } \\
2935\end{array}$ & B-S \\
\hline 19. & IC 476321 & GE-71 & LB-R & 53. & IC 403123 & AS 67 & B-S \\
\hline 20. & IC 476594 & GE-132 & LB-R & 54. & IE 7567 & Okhale 1 & $B-R$ \\
\hline 21. & IC 476517 & GE-496 & LB-R & 55. & IE 5066 & SDFM 208 & $B-R$ \\
\hline 22. & IC 475958 & GE-796 & B-R & 56. & IC 402886 & RPSP 738 & B-S \\
\hline 23. & IC 475531 & GE-1026 & B-R & 57. & IE 7509 & KAT/FM-1 & High B-R \\
\hline 24. & IC 476703 & GE-4440 & B-R & 58. & IE 2872 & ZM 552 & $\mathrm{~B}-\mathrm{R}$ \\
\hline 25. & IC 588005 & GE-4449 & B-R & 59. & IE 4491 & AMM 197 & $B-R$ \\
\hline 26. & IE 6537 & AOC 116 & $B-R$ & 60. & IE 5537 & Accn. No. 443 & $B-R$ \\
\hline 27. & IE 5091 & SDFM 313 & $B-R$ & 61. & IC 403074 & Gautami & $\mathrm{B}-\mathrm{R}$ \\
\hline 28. & IC 402475 & - & B-R & 62. & IE 4709 & МТВ 80 & High B-R \\
\hline 29. & IC 474413 & GE-5092 & $B-R$ & 63. & IE 894 & Gulu E & $\mathrm{B}-\mathrm{R}$ \\
\hline 30. & IE 4121 & UM 532 & B-R & 64. & IE 3499 & P 224 & $B-R$ \\
\hline 31. & - & GE-4975 & LB-S & 65. & IE 2957 & EC 140211 & $B-R$ \\
\hline 32. & - & TNAU 1231 & LB-S & 66. & IE 2821 & EC 132101 & $B-R$ \\
\hline 33. & IC 476673 & GE-201 & LB-S & 67. & IC 403254 & Tenda mandia & B-S \\
\hline 34. & IC 473994 & GE-5141 & LB-S & & & & \\
\hline
\end{tabular}

See Supplementary Table S1 for details of the finger millet accessions used in the study.

- , Accession no. not available; IC, indigenous collection existing at National Bureau of Plant Genetic Resources, India; IE, accession number of the global collection of finger millet germplasm from the International Crop research Institute for the Semi-Arid Tropics, India; EC, exotic collection existing in the NBPGR gene bank, India; LB-R, leaf blast resistant; LB-S, leaf blast susceptible; B-R, blast resistant; B-S, blast susceptible; F\&N B-R, finger and neck blast resistant.

content (PIC) of each loci was determined according to Roldan-Ruiz et al. (2000), and the resolving power (Rp) of each primer was calculated according to Prevost and Wilkinson (1999). Clustering analysis, pairwise genetic similarity coefficient based on Jaccard's similarity index and principal coordinate analysis (PCOA) were carried out separately on the SRAP and SSR-derived binary data using the Numerical Taxonomy and Multivariate Analysis System (NTSYSpc) Version 2.02e (Rohlf, 1998). Correlation of similarity matrices and goodness of fit of the dendrograms was measured by the Mantel test (Mantel, 1967) using 1000 permutations. The dendrograms 
were made using the unweighted pair-group method with an arithmetic average (UPGMA) procedure (Sneath and Sokal, 1973). The binary data were also analysed for PCoA using the same software. Bootstrap analysis with 500 permutations was carried out using the program WINBOOT (Yap and Nelson, 1996) to estimate the confidence of clustering in the branches of the dendrograms.

The software POPGENE v1.32 (Yeh and Boyle, 1999) was used to estimate the population level analysis, such as, the observed number of alleles $\left(N_{\mathrm{a}}\right)$, effective number of alleles $\left(N_{\mathrm{e}}\right)$, Nei's gene diversity $(b)$ and Shannon's information index $(I)$ within and among the 45 resistant and 22 susceptible genotypes of finger millet. The HardyWeinberg equilibrium was assumed, and 1000 simulated samples were used for the POPGENE analysis. Analysis of molecular variance (AMOVA) was carried out for both the SRAP and SSR data using the software Genetic Analysis in Excel (GenAlEx v6.41) to estimate the variance component within and between the resistant and susceptible finger millet genotypes (Peakall and Smouse, 2006) with 999 permutations.

\section{Results}

\section{Genetic diversity}

In the present study, out of the 154 SRAP primer combinations screened, 12 primer combinations produced clear and distinguishable bands across the 67 finger millet genotypes. These 67 finger millet genotypes were either varieties, cultivars, breeding materials or collections with previous records of blast disease tolerance from various sources such as, breeders assessment and varietal release notifications. Total 70 bands were scored ranging in size from 120 to $900 \mathrm{bp}$ (Table 2). The 12 SRAP primer combinations produced a minimum of two bands for the ME11-F/EM3-R primer combination and a maximum of eight bands for the primer combinations ME7-F/EM7-R, ME5-F/OD3-R and ME8-F/SA4-R. An average of five bands per primer combination was recorded. The range of polymorphism obtained from SRAP primer amplification was $75-100 \%$ with an average of $95.1 \%$. Out of the 12 SRAP primer combinations, 10 produced $100 \%$ polymorphic bands (Table 2 ). The overall range of band size in different alleles amplified by the 12 SSR primers was 150-300 bp. The 12 SSR primers produced total 34 alleles across the 67 genotypes with an average of 2.83 alleles per loci and a range of 2-4 alleles per loci (Table 2). Three private alleles i.e. alleles that did not occur in any other genotypes, were observed in genotype IE 4709 with the UGEP 15, UGEP 52 and UGEP 68 primers. Two alleles amplified each by the SSR primers UGEP 18 and UGEP 26, were considered rare alleles as they were found in $<5 \%$ of the finger millet genotypes. These alleles are useful to develop genotype-specific markers. Out of the total 34 alleles amplified by the 12 SSR primers, 32 were found to be polymorphic (94.1\%). The polymorphism percentage of the SSR primers across the 67 genotypes ranged from 50 to $100 \%$ with an average of $93.1 \%$.

The efficiency of the SRAP and SSR primers and the frequency of allelic diversity among the genotypes were measured through PIC and Rp values (Table 2). The PIC values of the SRAP and SSR markers used in the present study ranged from 0.12 to 0.46 (average 0.24 ) and 0.08 to 0.38 (average 0.25 ), respectively. Discriminating power of the SRAP and SSR primers, estimated through the Rp values, ranged from 1.73 to 6.93 and 1.20 to 4.81 , respectively. The mean number of bands or allele frequency (A) observed over a range of loci, provides a reasonable indication of the presence of allelic diversity within the population. In the present study, the observed values of allele frequencies were found from 0.19 to 0.79 and 0.20 to 0.88 for the SRAP and SSR primers, respectively. The above analysis of allele frequency and variability explains a range of genetic variations in resistant and susceptible finger millet genotypes using even a limited number of codominant markers.

\section{Cluster and PCoA}

The range of Jaccard's similarity coefficient values from the SRAP amplification data exhibited variations ranging from 0.57 (between INFM 95001 and PR-202) to 1.00 (between GE-4440 and GE-4449). In case of SSR primers, the similarity coefficient values ranged from 0.35 (between IE 4709 and INDAF 7) to 0.96 (between K-7 and GE-4920, IE 7509 and BAU 8, IE 7509 and GE-4987, and IE 4491 and GE-1026) accounting for an average 61\% variation. The UPGMA dendrograms formed from the SRAP and SSR primers showed different topologies and clusters of the finger millet genotypes (Fig. 1). The genotypes were separated at 0.57 and 0.50 similarity coefficient values, respectively, for the SRAP and SSR markers. Although the resistant and susceptible genotypes formed a mixed cluster, few resistant genotypes grouped together in small subclusters. The highly resistant finger millet genotype IE 4709 , which is an E. coracana sub species africana from Burundi, diverged from the other genotypes at the farthest similarity coefficient. Mantel correlation $(r)$ value between the SRAP and SSR-derived binary matrices was found $0.10(P=0.91)$. Goodness of fit of the dendrograms and the similarity matrices observed using the Mantels test for both the SRAP and SSR primers showed high correlations. The values observed was $r=0.83(P=1.0)$ and $r=0.73(P=1.0)$ for the SRAP and SSR data, respectively, which is a good fit. The PCoA agrees with that of the UPGMA dendrograms; i.e. an overall mixed grouping pattern was observed between the resistant and susceptible genotypes (Fig. 2). The 
Table 2. Details of the SRAP and SSR primers used in the study and their polymorphism statistics

\begin{tabular}{|c|c|c|c|c|c|c|c|}
\hline $\begin{array}{l}\text { Sl. } \\
\text { No. }\end{array}$ & Primer IDs & $\begin{array}{l}\text { Amplified band } \\
\text { range (bp) }\end{array}$ & $\begin{array}{l}\text { Total amplified } \\
\text { bands }\end{array}$ & $\begin{array}{l}\text { Polymorphic } \\
\text { bands (\%) }\end{array}$ & A & $\mathrm{PIC}$ & $\mathrm{Rp}$ \\
\hline & SRAP primers & & & & & & \\
\hline 1. & ME7-F/EM7-R & $150-550$ & 8 & 100 & 0.19 & 0.137 & 3.05 \\
\hline 2. & ME7-F/EM6-R & $180-700$ & 6 & 83.3 & 0.38 & 0.241 & 4.61 \\
\hline 3. & ME1-F/OD3-R & $200-280$ & 3 & 100 & 0.29 & 0.120 & 1.73 \\
\hline 4. & ME5-F/OD3-R & $120-600$ & 8 & 75 & 0.43 & 0.116 & 6.93 \\
\hline 5. & ME11-F/EM5-R & $150-700$ & 6 & 100 & 0.29 & 0.226 & 3.51 \\
\hline 6. & ME11-F/EM6-R & $150-600$ & 5 & 100 & 0.53 & 0.459 & 5.26 \\
\hline 7. & ME11-F/EM3-R & 150-280 & 2 & 100 & 0.79 & 0.393 & 3.15 \\
\hline 8. & ME8-F/SA4-R & $130-600$ & 8 & 100 & 0.36 & 0.271 & 5.83 \\
\hline 9. & ME11-F/EM7-R & 300-900 & 5 & 100 & 0.23 & 0.237 & 2.31 \\
\hline 10. & ME3-F/OD3-R & $150-600$ & 7 & 100 & 0.36 & 0.230 & 4.99 \\
\hline 11. & ME8-F/EM7-R & $250-600$ & 6 & 83.3 & 0.49 & 0.205 & 5.81 \\
\hline \multirow[t]{2}{*}{12.} & ME5-F/EM5-R & 200-800 & 6 & 100 & 0.34 & 0.282 & 4.13 \\
\hline & SSR primers & & & & & & \\
\hline 1. & UGEP12; SSR motif-(CT) 22 & $200-240$ & 3 & 100 & 0.20 & 0.285 & 1.20 \\
\hline 2. & UGEP15; SSR motif-(CT) 22 & $150-190$ & 3 & 100 & 0.23 & 0.198 & 1.41 \\
\hline 3. & UGEP18; SSR motif-(CT) 12 & $300-350$ & 2 & 100 & 0.45 & 0.268 & 1.80 \\
\hline 4. & UGEP19; SSR motif-(GA) ${ }_{18}$ & $250-300$ & 2 & 100 & 0.37 & 0.371 & 1.48 \\
\hline 5. & UGEP21; SSR motif-(GA) 16 & $200-250$ & 3 & 100 & 0.80 & 0.076 & 4.81 \\
\hline 6. & UGEP26; SSR motif-(CGG) 7 & $240-250$ & 2 & 100 & 0.42 & 0.384 & 1.68 \\
\hline 7. & UGEP52; SSR motif-(GA) 16 & $190-250$ & 3 & 66.7 & 0.63 & 0.318 & 3.77 \\
\hline 8. & UGEP53; SSR motif-(AG) 26 & $240-300$ & 3 & 100 & 0.35 & 0.299 & 2.10 \\
\hline 9. & UGEP67; SSR motif-(TC)22TT(GT)5 & $210-250$ & 3 & 100 & 0.45 & 0.129 & 2.68 \\
\hline 10. & UGEP68; SSR motif -(CT) 14 & $180-300$ & 4 & 100 & 0.34 & 0.185 & 2.72 \\
\hline 11. & UGEP77; SSR motif-CT) $)_{19}$ & $250-300$ & 2 & 50 & 0.88 & 0.158 & 3.51 \\
\hline 12. & UGEP81; SSR motif -(GT) 12 & $150-250$ & 4 & 100 & 0.41 & 0.348 & 3.31 \\
\hline
\end{tabular}

See Supplementary Table S2 for primer sequences.

F, forward primer; R, reverse primer; SRAP, sequence related amplified polymorphism; SSR, simple sequence repeat; UGEP, SSR primers from Dida et al. (2007); A, average number of alleles per primer; PIC, polymorphic information content; Rp, resolving power.

aggregates from the first three coordinates correspond to 29.7 and $43.8 \%$ of the total cumulative variance observed with the SRAP and SSR primers, respectively. This suggests the PCoA analysis could be used to estimate the genetic relationships among finger millet genotypes. From the PCoA plot, it is speculated that diverse finger millet genotypes, which were placed in different groups can be hybridized for a combination of genotypes.

\section{Population variation analysis}

For population genetic analysis, the 67 finger millet genotypes were assorted by resistant and susceptible groups, according to breeders' assessment and published information
(Rajanna et al., 2000; Mantur et al., 2001; Nagaraja et al., 2007; Babu et al., 2013; Babu et al., 2014). Assuming Hardy-Wienberg equilibrium, single and multiple population-level statistics were derived by scoring the SRAP and SSR bands as dominant diploid markers (Table 3). Using SRAP markers, the resistant and susceptible groups separately displayed 84.3 and $70 \%$ polymorphic loci, respectively, with the total polymorphic loci being 94.3\%. The SSR genotyping revealed $79.4 \%$ and $50.0 \%$ polymorphic loci, respectively, for the resistant and susceptible groups with a total polymorphic loci of $79.4 \%$. The mean estimates of observed alleles $\left(N_{\mathrm{a}}\right)$ and effective alleles $\left(N_{\mathrm{e}}\right)$ between the resistant and susceptible genotypes varied moderately, for both the SRAP and SSR data 

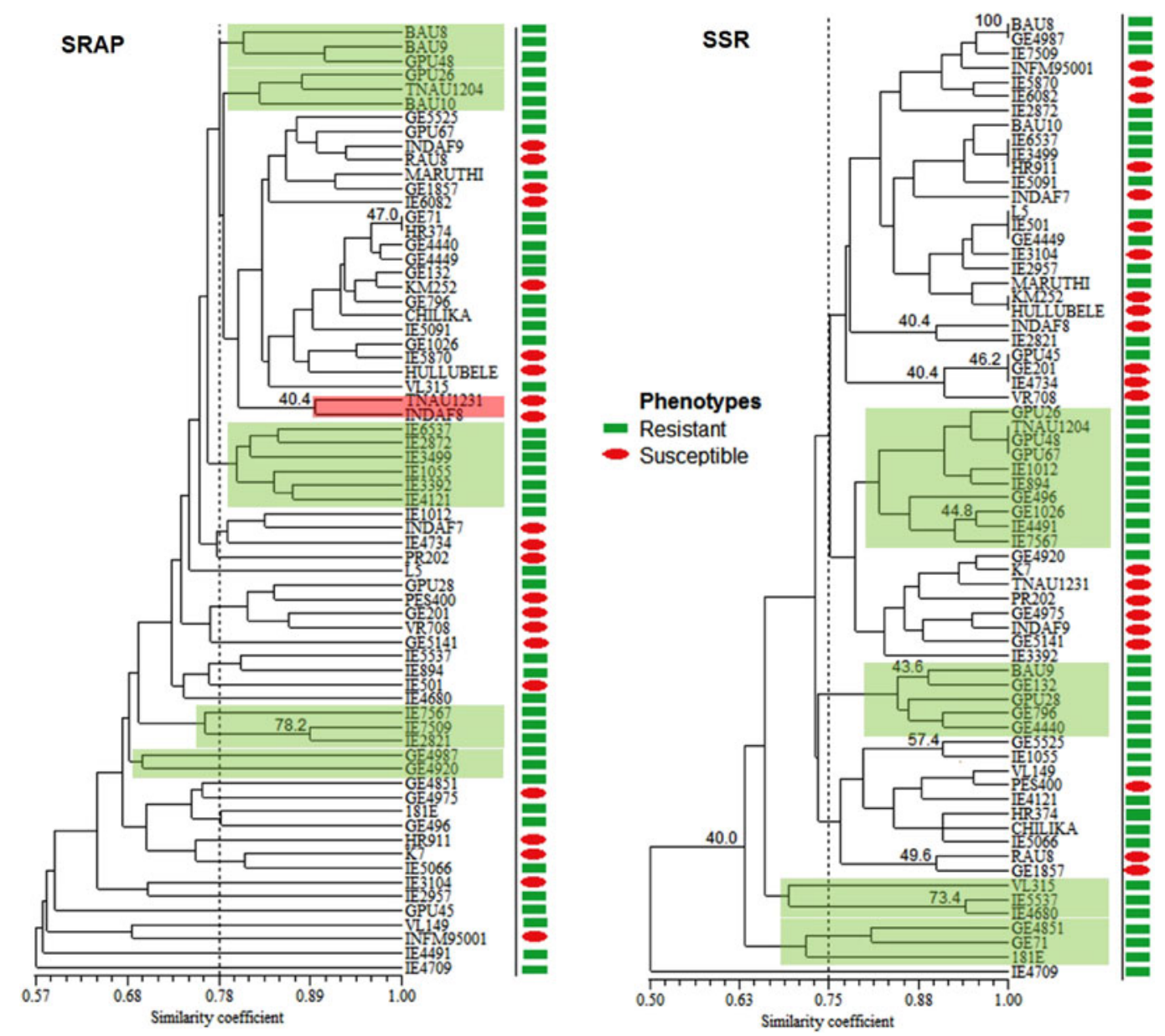

Fig. 1. The similarity coefficient-based UPGMA clustering dendrograms of the 67 finger millet genotypes using SRAP and SSR primers. The green bar and red ovals represent resistance and susceptibility to fungal blast disease associated with specific genotypes. The bootstrap values of $\geq 40.0$ were depicted on the branch nodes. See colour figure online.

(Table 3). According to the SRAP genotyping, the mean heterozygosity or the gene diversity $(b)$ varied slightly, 0.23 \pm 0.20 and $0.21 \pm 0.21$, respectively, between the resistant and susceptible genotypes, which is similar to the average gene diversity of $0.23 \pm 0.20$ in the total population. Using the data obtained from SSR genotyping, the gene diversity (b) between the resistant and susceptible genotypes ranged from $0.21 \pm 0.18$ and $0.15 \pm 0.18$, respectively with a total gene diversity of $0.20 \pm 0.18$. AMOVA was performed between and within the resistant and susceptible groups using both SRAP and SSR genotyping data (Table 4). Comparison between the resistant and susceptible groups revealed 6 and 2\% of genetic variations, respectively, for the SRAP and SSR primers. Nevertheless, a high genetic variation of 94 and $98 \%$, respectively, in the SRAP and SSR genotyping data, was observed within the groups. The pairwise estimates of variance $\left(\Phi_{\mathrm{PT}}\right)$ were observed low, $0.057(P=0.002)$ using SRAP and $0.024(P=0.051)$ using SSR data, which shows about the confidence of the data points close to the mean value.

\section{Discussion}

The results from the present study showed how two different molecular markers, SRAP and SSR, were used to explore the genetic diversity pattern among the 67 finger millet genotypes that differ in response to fungal blast disease. Previous estimates of genetic diversity (Babu et al., 2007) and population genetic structure in finger millet (Arya et al., 2013) were related to geographical accessions irrespective of any specific phenotypic trait. Our study reports genetic variation within finger millet genotypes that were classified as resistant or susceptible to fungal blast disease and are of various pedigree and origins. In a contemporary study by Babu et al. (2014), EST-SSR markers were developed using comparative genomic information from disease resistant genes of rice. They further carried out an association analysis of the blast disease resistant and susceptible phenotypes in several global finger millet accessions, in which approximately $30 \%$ of the genotypes used in the present study also coincided. In the present study, we 


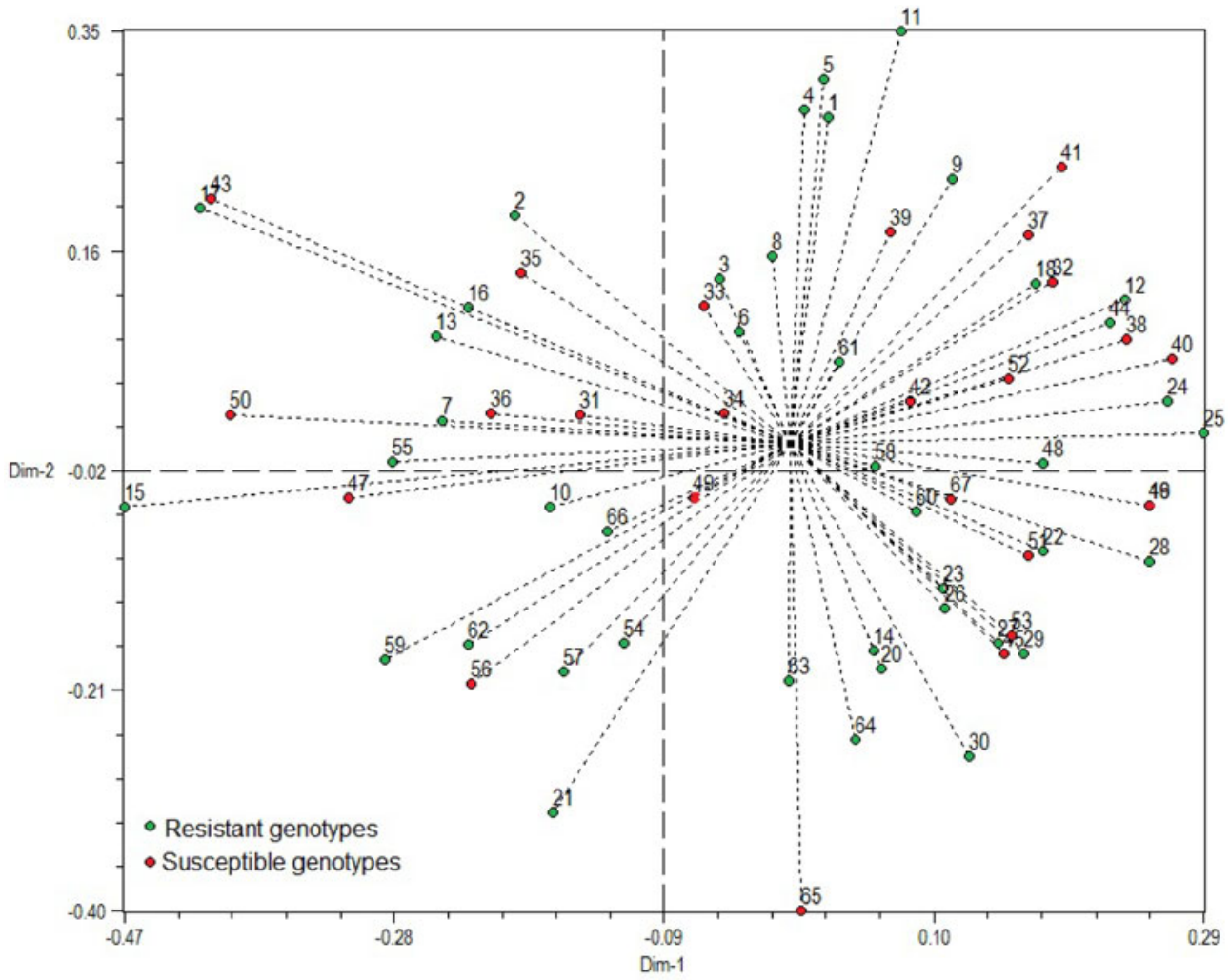

SRAP

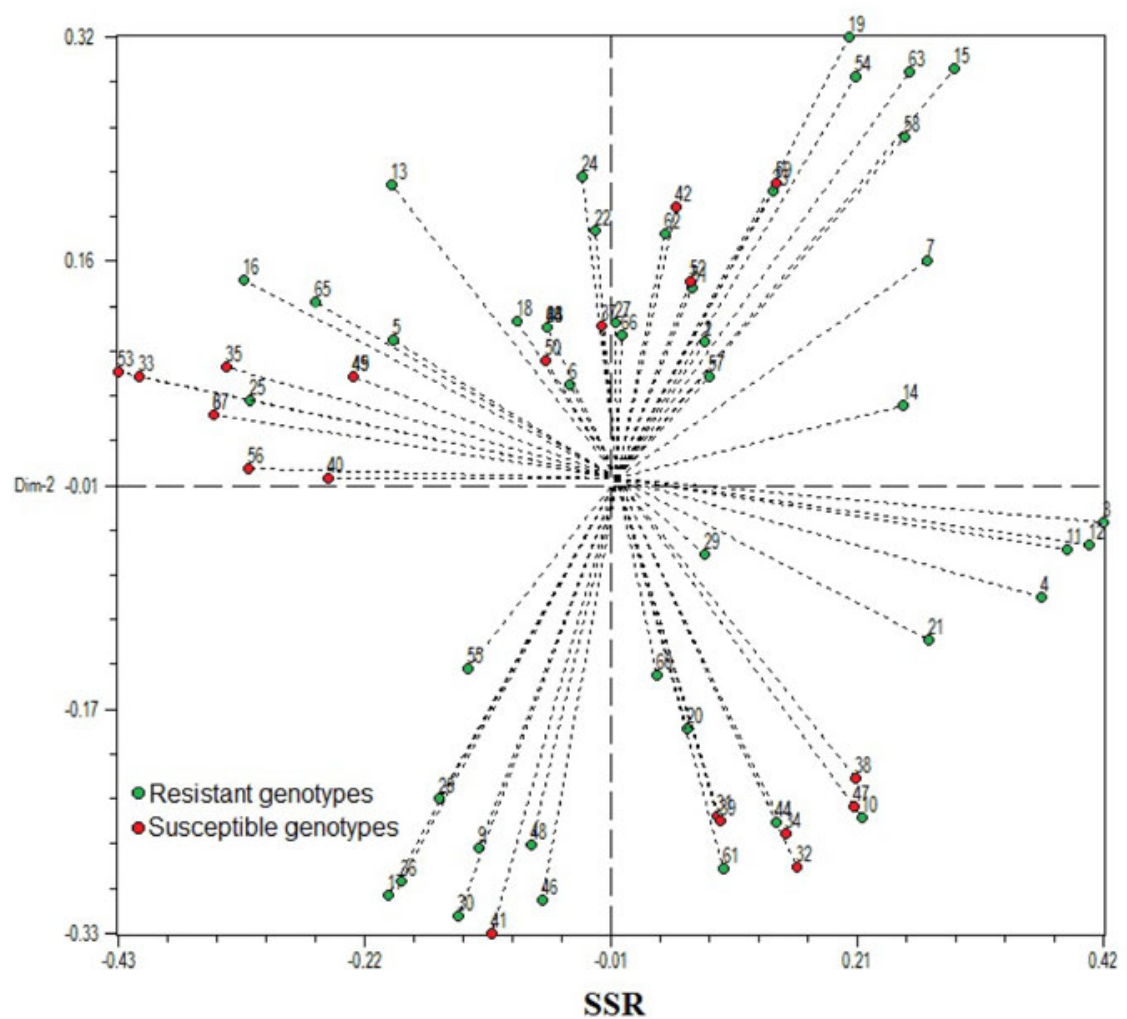

Fig. 2. Principal coordinate (PCoA) diagrams showing genetic polymorphism among the 67 finger millet genotypes derived from SRAP and SSR data. The resistant genotypes and susceptible genotypes were filled with green and red circles, respectively. See colour figure online. 


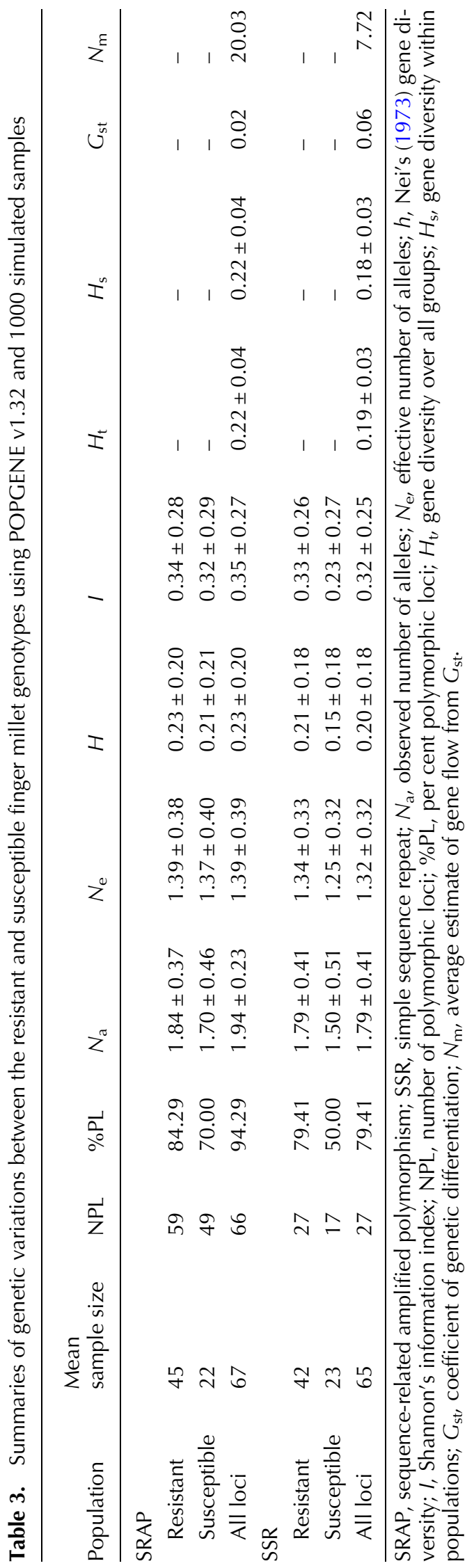

employed simple PCR-based genomic SSR and SRAP markers to assess primary level information on the genetic variations of the resistant and susceptible finger millet genotypes. Most of the finger millet genotypes used in the study were from the Indian National Agricultural Research system collections. Thus, the results from the present study may serve as a supplementary data to the existing molecular genetic diversity of finger millet genotypes differing in response to fungal blast disease.

The average band polymorphism among the 67 finger millet genotypes used in the present study were found high for both SRAP (>95\%) and SSR primers (>93\%) with an average of 5 and 2.83 bands per primer, respectively. However, the PIC values and other marker discrimination indices, such as Rp and allelic richness were found to be in moderate ranges. Our results of overall PIC values are in conformity to the PIC values reported in finger millet from other diversity analyses (Panwar et al., 2010; Babu et al., 2014; Nirgude et al., 2014). Considering finger millet a self-pollinated crop, the genetic diversity estimates based on gene diversity $(b)$, Shannon's index (I) and genetic differentiation coefficient $\left(G_{\mathrm{st}}\right)$ were found to vary reasonably between the resistant and susceptible genotypes. Gene diversity did not differ much when estimated in overall and within populations, but the gene flow measures $\left(N_{\mathrm{m}}\right)$ were found to be high between the resistant and susceptible groups. This might be explained because many of the present-day cultivars or genotypes have a lineage from ancestral E. coracana sub sp. africana genome (Dida and Devos, 2006).

Based on pairwise Jaccard's similarity coefficient values, the pairs of finger millet genotypes with the highest and lowest similarity coefficients were identified using data generated from SRAP primers. Accessions INFM 95001 and PR-202 were identified as highly diverse genotypes (similarity index $0.4 \%$ ), which are both susceptible to the blast disease. This is expected because of the origin of these genotypes; the former is developed from an African genetic donor, whereas the latter is from an Indian accession. The Indian germplasm GE-4440 and GE-4449, both reported as resistant to the blast disease, were found to have maximum genetic similarity index (98\%). Both these genotypes were originated from the Orissa state of India, which possibly is reflected in their genomic similarity. Compared with the SRAP genotyping data, the pairwise genetic similarity index generated by SSR markers could distinguish better between the resistant and susceptible genotypes. The highest genetic diversity (similarity index 0.4\%) was noted between the resistant IE 4709 genotype from Burundi and susceptible genotype INDAF 7 from India. The IE 4709 genotype is an E. coracana sub species africana, a wild relative, also known for its higher grain nutrient content, while INDAF 7 has a higher yield potential and cold tolerance (Upadhyaya et al., 2011). Hence, 
Table 4. Analysis of molecular variance (AMOVA) in 67 finger millet genotypes considering two groups, resistant and susceptible

\begin{tabular}{|c|c|c|c|c|c|c|c|}
\hline Source of variance & $\mathrm{df}$ & SS & MS & Estimated variance & $\%$ Variance & $\Phi_{\mathrm{PT}}$ & $P$ \\
\hline \multicolumn{8}{|l|}{ SRAP } \\
\hline Among group & 1 & 17.466 & 17.466 & 0.373 & 6 & 0.057 & 0.002 \\
\hline Within group & 65 & 402.833 & 6.197 & 6.197 & 94 & & \\
\hline Total & 66 & 420.299 & & 6.570 & 100 & & \\
\hline \multicolumn{8}{|l|}{ SSR } \\
\hline Among group & 1 & 6.001 & 6.001 & 0.085 & 2 & 0.024 & 0.051 \\
\hline Within group & 65 & 223.969 & 3.446 & 3.446 & 98 & & \\
\hline Total & 66 & 229.970 & & 3.530 & 100 & & \\
\hline
\end{tabular}

SRAP, sequence-related amplified polymorphism; SSR, simple sequence repeat; $\mathrm{df}$, degrees of freedom; SS, sum of squares; MS, mean of squares; $\Phi_{\mathrm{PT}}$, pair wise population structure; $P$, random probability value.

these diverse genotypes may serve as effective parents in breeding programs for desirable agronomic traits like disease resistance, grain nutrient and yield. Clustering based on UPGMA and analysis of principle coordinates suggested different topologies and placed the finger millet genotypes in mixed and broad clusters. At the subcluster level, few resistant and susceptible genotypes clustered together. The results from UPGMA analysis also identified IE 4709, the highly blast disease resistant genotype from Burundi, as the most diverse from the other finger millet genotypes. The divergence of the IE 4709 genotype from all other finger millet genotypes was observed at $\sim 50 \%$ similarity coefficient value. Similar divergence of the IE 4709 genotype from other cultivated finger millets was also reported through RAPD markers (Malambane et al., 2013). Although no clear distinction of resistance and susceptible genotypes was observed in PCoA analysis, the first three coordinates produced $>25 \%$ contribution to the total genetic variation, which is a good measure of selecting diverse genotypes for hybridization experiments (Mohammadi and Prasanna, 2003). Thus, PCoA analysis can be employed to select diverse resistant and susceptible finger millet genotypes for development of mapping populations. The population genetic parameters and AMOVA analysis showed 2-6\% genetic variation between the resistant and susceptible groups compared with $96-98 \%$ genetic variation observed within the groups. Similar differences in variation between resistant and susceptible genotypes of soybean to rhizoctonia root rot disease were reported (Tomar et al., 2011) or between and within rust-resistant genotypes of orchard grass (Zeng et al., 2014).

In conclusion, we report a molecular characterization of genetic diversity among and within finger millet genotypes differing in resistance and susceptibility response to fungal blast disease. Although genotypes that differ in their resistance to blast did not cluster into any particular group, a few consistent genetically diverse resistant and susceptible genotypes were identified. Especially, the resistant IE 4709 and susceptible INDAF 7 were identified as the most genetically diverse genotypes among the accessions used in the study. Interestingly, few unique SSR alleles were also identified specific for the resistant IE 4709 genotype. These genotypes can be potentially employed in developing mapping populations for tagging resistance genes, generating efficient markers and strategic markerassisted breeding for fungal blast disease resistance. Given the genomic resources and techniques in finger millet are scanty, the present study is an important steppingstone for finger millet genetics and resistance breeding program.

\section{Supplementary material}

To view supplementary material for this article, please visit http://dx.doi.org/10.1017/S1479262116000010

\section{Acknowledgements}

Authors thank National Bureau of Plant Genetic Resources, New Delhi, the All India Co-ordinated Small Millets Improvement Project, Bengaluru and the International Crops Research Institute for the Semi-Arid Tropics, Hyderabad for providing finger millet accessions. The research support provided by the Head, Division of Genomic Resources and Director, NBPGR is also acknowledged. Authors are grateful to Dr Savithri Nambeesan, Assistant Research Scientist, University of Georgia, Athens, USA for language correction of the article.

\section{References}

Arya L, Verma M, Gupta VK and Seetharam A (2013) Use of genomic and genic SSR markers for assessing genetic 
diversity and population structure in Indian and African finger millet (Eleusine coracana (L.) Gaertn.) germplasm. Plant Systematics and Evolution 299: 1395-1401.

Babu BK, Senthil N, Gomez SM, Biji KR, Rajendraprasad NS, Satheesh Kumar S and Babu RC (2007) Assessment of genetic diversity among finger millet (Eleusine coracana (L.) Gaertn.) accessions using molecular markers. Genetic Resources and Crop Evolution 54: 399-404.

Babu TK, Thakur RP, Reddy PN, Upadhyaya HD, Girish AG and Sarma NDRK (2012) Development of a field screening technique and identification of blast resistance in finger millet core collection. Indian Journal of Plant Protection 40: 45-51.

Babu TK, Thakur RP, Upadhyaya HD, Reddy PN, Sharma R, Girish AG and Sarma NDRK (2013) Resistance to blast (Magnaporthe grisea) in a mini-core collection of finger millet germplasm. European Journal of Plant Pathology 135: 299-311.

Babu BK, Dinesh P, Agrawal PK, Sood S, Chandrashekara C, Bhatt JC and Kumar A (2014) Comparative genomics and association mapping approaches for blast resistant genes in finger millet using SSRs. PLOS ONE 9: e99182. doi: 10.1371/journal. pone.0099182

Chethan S and Malleshi NG (2007) Finger millet polyphenols: characterization and their nutraceutical potential. American Journal of Food Technology 2: 618-629.

Dida MM and Devos KM (2006) Finger millet. In: Kole C (ed.) Cereals and Millets. NY, New York: Springer, pp. 333-343.

Dida MM, Srinivasachary Ramakrishnan S, Bennetzen JL, Gale MD and Devos KM (2007) The genetic map of finger millet, Eleusine coracana. Theoretical and Applied Genetics 114: 321-332.

Dida MM, Wanyera N, Harrison Dunn ML, Bennetzen JL and Devos KM (2008) Population structure and diversity in finger millet (Eleusine coracana) germplasm. Tropical Plant Biology 1: 131-141.

Doyle JJ and Doyle JL (1990) Isolation of plant DNA from fresh tissue. Focus 12: 13-15.

Fakrudin B, Shashidhar HE, Kulkarni RS and Hittalmani S (2004) Genetic diversity assessment of finger millet, Eleusine coracana (Gaertn.), germplasm through RAPD analysis. PGR Newsletter 138: 50-54.

Gowda J, Suvarna, Somu G, Bharathi S and Mathur PN (2007) Formation of core set in finger millet (Eleusine coracana (L.) Gaertn.) germplasm using geographical origin and morphoagronomic characters. Indian Journal of Plant Genetic Resources 20: 38-42.

Lenne JM, Takan JP, Wanyera N, Manyasa EO, Mgonja MA, Okwadi J, Brown AE and Sreenivasaprasad S (2007) Finger millet blast management: a key entry point for fighting malnutrition and poverty in East Africa. Outlook on Agriculture 36: 101-108. http://dx.doi.org/10.5367/000000007781159994

Li G and Quiros CF (2001) Sequence-related amplified polymorphism (SRAP), a new marker system based on a simple PCR reaction: its application to mapping and gene tagging in Brassica. Theoretical and Applied Genetics 103: 455-461. doi: 10.1007/s001220100570

Malambane G, Jaisil P, Sanitchon J, Suriharn B and Jothityangkoon D (2013) Evaluation of genetic variation among finger millet (Eleusine coracana L. Gaertn) accessions using RAPD markers. SABRAO Journal of Breeding and Genetics 45: 231-239.

Mantel N (1967) The detection of disease clustering and generalized regression approach. Cancer Research 27: 209-220.

Mantur SG, Vishwanath S and Anilkumar TB (2001) Evaluation of finger millet genotypes for resistance to blast. Indian Phytopathology 54: 38-41.
Mbithi-Mwikya S, Ooghe W, Van Camp J, Nagundi D and Huyghebaert A (2000) Amino acid profile after sprouting, autoclaving and lactic acid fermentation of finger millet (Eleusine coracana) and kidney beans (Phaseolus vulgaris L.). Journal of Agricultural Food Chemistry 48: 3081-3085.

Mohammadi SA and Prasanna BM (2003) Analysis of genetic diversity in crop plants-salient statistical tools and considerations. Crop Science 43: 1235-1248.

Nagaraja A, Jagadish PS, Ashok EG and Krishne Gowda KT (2007) Avoidance of finger millet blast by ideal sowing time and assessment of varietal performance under rainfed production situations in Karnataka. Journal of Mycopathological Research 46: 109-111.

Nagaraja A, Kumar B, Raguchander T, Hota AK, Patro TSSK, Gowda D., Savita E and Gowda MVC (2012) Impact of disease management practices on finger millet blast and grain yield. Indian Phytopathology 65: 356-359.

Nakayama H, Nagamine T and Hayashi N (2005) Genetic variation of blast resistance in foxtail millet (Setaria italica (L.) P. Beauv.) and its geographic distribution. Genetic Resources and Crop Evolution 52: 863-868.

Nei M (1973) Analysis of gene diversity in subdivided populations. Proceedings of National Academy of Sciences of the United States of America 70: 3321-3323.

Nirgude M, Babu BK, Shambhavi Y, Singh UM, Upadhyaya HD and Kumar A (2014) Development and molecular characterization of genic molecular markers for grain protein and calcium content in finger millet (Eleusine coracana (L.) Gaertn.). Molecular Biology Reporter 41: 1189-200.

Panwar P, Nath M, Yadav VK and Kumar A (2010) Comparative evaluation of genetic diversity using RAPD, SSR and cytochrome P450 gene based markers with respect to calcium content in finger millet (Eleusine coracana L. Gaertn.). Journal of Genetics 89: 121-133.

Peakall R and Smouse PE (2006) GENALEX 6: genetic analysis in Excel. Population genetic software for teaching and research. Molecular Ecology Notes 6: 288-295.

Prajapati VP, Sabalpara AN and Pawar DM (2013) Assessment of yield loss due to finger millet blast caused by Pyricularia grisea (Cooke) Sacc. Trends in Biosciences 6: 876-878.

Prevost A and Wilkinson MJ (1999) A new system of comparing PCR primers applied to ISSR fingerprinting of potato cultivars. Theoretical and Applied Genetics 98: 107-112.

Rajanna MP, Rangaswamy BR, Basavaraju MK, Karegowda C and Ramaswamy GR (2000) Evaluation of finger millet genotypes for resistance to blast caused by Pyricularia grisea Sacc. Plant Disease Research 15: 199-201.

Rao ANS (1990) Estimates of losses in finger millet (Eleusine coracana) due to blast disease (Pyricularia grisea). Mysore Journal of Agricultural Sciences 24: 57-60.

Roldan-Ruiz I, Dendauw J, Van Bockstaele E, Depicker A and De Loose M (2000) AFLP markers reveal high polymorphic rates in ryegrasses (Lolium spp.). Molecular Breeding 6: $125-134$

Rohlf FJ (1998) NTSYSPc Numerical Taxonomy and Multivariate Analysis System Version 2.0 User Guide. Applied Biostatistics Inc, Setauket, New York, pp. 37.

Salimath SS, de Oliveira AC, Godwin ID and Bennetzen JL (1995) Assessment of genome origins and genetic diversity in the genus Eleusine with DNA markers. Genome 38: $757-763$

Singh P and Raghuvanshi RS (2012) Finger millet for food and nutritional security. African Journal of Food Sciences 64: $77-84$. 
Sneath P and Sokal R (1973) Numerical Taxonomy. San Francisco: WH Freeman.

Takan JP, Chipili J, Muthumeenakshi S, Talbot NJ, Manyasa EO, Bandyopadhyay R, Sere Y, Nutsugah SK, Talhinhas P, Hossain M, Brown AE and Sreenivasaprasad S (2012) Magnaporthe oryzae populations adapted to finger millet and rice exhibit distinctive patterns of genetic diversity, sexuality and host interaction. Molecular Biotechnology 50: $145-158$.

Tomar J, Saini N, Goyal BS, Tripathi N, Shrivastava AN, Verma RK and Tiwari S (2011) Assessment of genetic diversity among rhizoctonia root rot resistant soybean genotypes. Journal of Food Legumes 24: 267-272.

Upadhyaya HD, Sarma NDRK, Ravishankar CR, Albrecht T, Narasimhudu Y, Singh SK, Varshney SK, Reddy VG, Singh S, Dwivedi SL, Wanyera N, Oduori COA, Mgonja MA, Kisandu DB, Parzies HK and Gowda CLL (2010) Developing a mini-core collection in finger millet using multilocation data. Crop Science 50: 1924-1931.
Upadhyaya HD, Ramesh S, Sharma S, Singh SK, Varshney RK, Sarma NDRK, Ravishankar CR, Narasimhudu Y, Reddy VG, Sahrawat KL, Dhanalakshmi TN, Mgonja MA, Parzies HK, Gowda CLL and Singh S (2011) Genetic diversity for grain nutrients contents in a core collection of finger millet (Eleusine coracana (L.) Gaertn.) germplasm. Field Crops Research 121: 42-52.

Yap IV and Nelson RJ (1996) Winboot: A Program for Performing Bootstrap Analysis of Binary Data to Determine the Confidence of UPGMA-Based Dendrograms. Manilla, Phillipines: IRRI.

Yeh FC and Boyle TJB (1999) POPGENE version 1.3.2: Microsoft window-based freeware for population genetic analysis. http://www.ualberta.ca/ fyeh/index.htm

Zeng B, Zhang Y, Huang L, Jiang X, Luo D and Yin G (2014) Genetic diversity of orchard grass (Dactylis glomerata L.) germplasms with resistance to rust diseases revealed by start codon targeted (SCOT) markers. Biochemical Systematics and Ecology 54: 96-102. 